\title{
Survival, Host-Pathogen Interaction, and Management of Macrophomina phaseolina on Strawberry in Israel
}

Aida Zveibil, Department of Plant Pathology and Weed Research, ARO, The Volcani Center; Neta Mor and Nabeel Gnayem, Extension Service, Ministry of Agriculture and Rural Development; and Stanley Freeman, Department of Plant Pathology and Weed Research, ARO, The Volcani Center, Bet Dagan 50250, Israel

\begin{abstract}
Zveibil, A., Mor, N., Gnayem, N., and Freeman, S. 2012. Survival, host-pathogen interaction, and management of Macrophomina phaseolina on strawberry in Israel. Plant Dis. 96:265-272.

Crown and root rot of strawberry, caused by Macrophomina phaseolina, have become predominant soilborne diseases of strawberry in Israel over the past 5 years. In total, 151 isolates of the pathogen were isolated from infected strawberry plants of commercially grown cultivars in Israel onto a modified agar medium for the genus Macrophomina. Sclerotia viability declined more rapidly in soil maintained at $25^{\circ} \mathrm{C}$ or at soil temperatures fluctuating from 18 to $32^{\circ} \mathrm{C}$ under greenhouse conditions, compared with sclerotia viability in soil kept at $30^{\circ} \mathrm{C}$. After 30 to 40 weeks of exposure in soil, inocula maintained at 25 or $30^{\circ} \mathrm{C}$ or at fluctuating temperatures in a greenhouse declined to negligible levels. A significant increase in plant mortality was observed in infested soils maintained at 30 versus $25^{\circ} \mathrm{C}$, whereas water stress at 25 or $30^{\circ} \mathrm{C}$ did not affect plant mortality in M. phaseolina-infested

soils. This demonstrated the importance of elevated soil temperature, not moisture stress, on plant mortality caused by $M$. phaseolina. Host specificity was not evident when strawberry plants were inoculated with each of seven Israeli isolates of $M$. phaseolina obtained from six other plant species, suggesting the importance of keeping strawberry crops out of rotation with other host crops of the pathogen. The soil fumigants methyl bromide (applied at $500 \mathrm{~kg} / \mathrm{ha}$ ) and metam sodium (730 liter/ha) caused 90 and $95 \%$ pathogen mortality in field experiments, respectively, indicating that fumigation may be an effective method of managing this pathogen in infested soils. The increase in prevalence of crown and root rot caused by M. phaseolina in strawberry crops in Israel may be related to the phase-out of methyl bromide.
\end{abstract}

Strawberry (Fragariae $\times$ ananassa Duch.) is cultivated in open fields or in greenhouses as an annual, winter, fresh-market crop in warm areas of the United States, such as California and Florida (34), and the Mediterranean region, such as Israel $(8,10)$. In Israel, nuclear stock and foundation plants are indexed for viruses and monitored for major soilborne fungal pathogens (e.g., Phytophthora spp., Rhizoctonia spp., Colletotrichum spp., Verticillium spp., and Macrophomina phaseolina) twice a year. Spring-propagated field nurseries are routinely monitored for the same pathogens until summer transplanting to fruiting fields throughout the winter and spring of the following year $(8,9,32,40)$. At the end of the growing season in late spring, plants are destroyed by mowing off the tops, plowing the plants into the soil, or applying herbicides (34). Alternatively, plants may be removed individually by uprooting. In all cases, the debris of plants infected by soilborne pathogens may remain in the soil until the following growing season and, thus, serve as a potential source of primary inoculum for new crops (8).

M. phaseolina (Tassi) Goid. affects a wide range of plants and appears in many geographic locations worldwide (23). Some of the earliest records of the pathogen affecting strawberry were from India and Egypt, where high soil temperatures (33 to $47^{\circ} \mathrm{C}$ ) and low soil moisture conditions prevail $(15,17,18)$. However, additional outbreaks have been recorded from cooler, more temperate regions (soil temperatures of 8 to $27^{\circ} \mathrm{C}$ ) such as Spain and France $(1,2)$. More recent incidences of epidemics in strawberry have been reported from the United States, specifically in California (14) and Florida (21), as well as from Israel (39) and elsewhere in the Mediterranean, such as Turkey (3) and Greece (36). Control of $M$.

Corresponding author: S. Freeman, E-mail: freeman@ volcani.agri.gov.il

Accepted for publication 27 September 2011.

http://dx.doi.org/10.1094/PDIS-04-11-0299

(C) 2012 The American Phytopathological Society phaseolina is difficult due, in part, to heat tolerance of the pathogen and the fact that sclerotia are resilient resting structures $(20,29)$. The standard practice of soil fumigation before establishing strawberry nursery plants and transplants in production fields has been based on the availability of methyl bromide $(8,10,17)$. However, the phase-out of uses of this fumigant in most developed countries, including Israel, appears to have led to an increase in incidence of $M$. phaseolina infections in strawberry crops $(1,14,21,39)$. Recently, combinations of soil amendments and soil solarization have shown promise for control of the pathogen under arid field conditions $(16,26)$; however, the use of alternative measures to methyl bromide fumigation have not always been effective $(1,14,20,21,33,39)$.

Environmental factors such as water stress and, especially, heat can predispose crops to M. phaseolina in temperate regions (23). In sorghum, water stress increased Macrophomina wilting (5). Similarly, water stress enhanced charcoal rot in common bean (19). In a study by Edmunds (6), grain sorghum mortality was greater at 40 than $35^{\circ} \mathrm{C}$ when plants were inoculated with $M$. phaseolina. Papavizas (27) stressed that soil moisture and water level have significant effects on survival of sclerotia of M. phaseolina. High soil moisture and flooding caused a decline in sclerotia viability compared with dry soils $(4,28)$. Moreover, soil heating and irrigation increased soil temperatures from 50 to $57^{\circ} \mathrm{C}$ at $0-$ to $30-\mathrm{cm}$ depths, resulting in approximately $70 \%$ reduction in sclerotia viability (16). Likewise, $M$. phaseolina sclerotia viability was reduced by soil solarization at $50^{\circ} \mathrm{C}$ in naturally infested soils (26).

Although the genus Macrophomina contains only one known species, M. phaseolina, the fungus is a cosmopolitan pathogen affecting $>500$ botanical species $(23,29)$. No host specialization was evident for isolates of $M$. phaseolina from soybean, sorghum, or cotton (35). In contrast, isolates of M. phaseolina from a population in Mexico displayed a preference for common bean (19). Although $M$. phaseolina is a heterogeneous species that cannot be delineated into distinct, subspecific groups, isolates colonizing members of the family Poaceae appeared to be more restricted in pathogenicity than the general population (25). Various molecular 
methods based on random amplified polymorphic DNA analyses, restriction fragment length polymorphisms of ribosomal DNA internal transcribed spacer regions, amplified fragment length polymorphisms, and repeat sequence polymerase chain reaction assays have indicated that genetic diversity exists in M. phaseolina $(13,35)$. Understanding $M$. phaseolina host specialization is extremely important for managing this disease in areas such as Israel, due to close proximity of cultivation or rotations of various crops that are hosts of this pathogen. For example, M. phaseolina has been detected in pine seedlings (31), melon (30), and strawberry (39), which are cultivated in close proximity in areas such as the Sharon region of Israel. Likewise, M. phaseolina isolates from melon were capable of causing mortality of bean and corn plants in inoculation experiments (7).

Based on numerous recent reports of crown and root rot of strawberry worldwide, this study was conducted to (i) evaluate survival of sclerotia of $M$. phaseolina under different soil conditions, (ii) determine the effect of soil moisture and heat stress of plants on mortality caused by M. phaseolina (to mimic the stress that strawberry plants are subjected to during transplanting from nursery to productions fields), (iii) determine host specialization of isolates from various crops cultivated in close proximity with strawberry in Israel, and (iv) evaluate potential alternatives to methyl bromide soil fumigation for management of different types of inocula of the pathogen in the field because this fumigant has recently been phased out of use in Israel.

\section{Materials and Methods}

Fungal isolates and growth conditions. A representative isolate of $M$. phaseolina from strawberry (M1, originating from necrotic, wilted crowns of 'Yuval' strawberry from the Sharon region of central Israel, and used in Koch's postulate studies; 39), from a total of 151 isolates in the authors' collection, was used for survival and pathogenicity studies. Two additional isolates (M2 and M3, isolated from 'Tamar' strawberry in the Sharon region) from a previous study (39), and a fourth isolate (M9, from the 'Hadas' strawberry in the Sharon region) were used in some experiments to verify results obtained for isolate M1. The isolates were incubated at $25^{\circ} \mathrm{C}$ for 5 to 7 days in the dark on potato dextrose agar (PDA; Difco Laboratories, Detroit) medium containing chloramphenicol at $250 \mathrm{mg} / \mathrm{liter}$.

Modified agar medium for isolation and enumeration of $M$. phaseolina propagules from soil. A modified agar medium for $M$. phaseolina isolation from soil was formulated based on that of Mathur's MS semiselective agar medium for Colletotrichum spp. (9,22,24,37): $0.1 \%$ yeast extract, $0.1 \%$ bactopeptone, $1 \%$ sucrose, $0.25 \% \mathrm{MgSO}_{4} \cdot 7 \mathrm{H}_{2} \mathrm{O}, 0.27 \% \mathrm{KH}_{2} \mathrm{PO}_{4}, 2 \%$ agar, and Rose Bengal at $90 \mathrm{mg} /$ liter, supplemented after autoclaving with iprodione at 2.5 mg (a.i.)/liter (Rovral 50\% WP; Rhone Poulenc, Lyon, France), chloramphenicol at $250 \mathrm{mg} / \mathrm{liter}$, dihydrostreptomycin at 250 $\mathrm{mg} /$ liter, and $0.1 \%$ lactic acid. The medium was subsequently used for routine isolation of the pathogen from diseased tissues and enumeration of different types of inocula of $M$. phaseolina (i.e., naturally infected stolons and crowns, and sclerotia produced on the agar medium in the laboratory).

Inocula preparation. Sclerotia. Ten small disks $\left(0.5 \mathrm{~cm}^{2}\right)$ cut from the edges of 7-day-old colonies of M. phaseolina growing on PDA medium were placed in each 250-ml Erlenmyer flask containing $100 \mathrm{ml}$ of potato dextrose broth (PDB; Difco Laboratories) amended with chloramphenicol at $250 \mathrm{mg} / \mathrm{liter}$, and incubated in the dark at $25^{\circ} \mathrm{C}$ for 10 days. Thereafter, $0.01 \%$ Tween (SigmaAldrich, St. Louis) was added to the suspension containing mycelia and sclerotia, and the suspension was blended for $30 \mathrm{~s}$ and filtered through Miracloth (Calbiochem, La Jolla, CA). The Miracloth containing sclerotia was dried at $25^{\circ} \mathrm{C}$ in an incubator for 3 days and filtered through a 2 -mm-diameter sieve into a glass beaker. The number of sclerotia per unit area was determined by dilution plating, and viability of sclerotia was tested on the modified agar medium for M. phaseolina. Sclerotia were collected and used for survival and soil fumigation experiments in the field.
Stolons. Naturally infected stolons of 'Tamar' strawberry were collected from plants in an infected nursery in the Sharon area of Israel in May 2006 and stored at $4{ }^{\circ} \mathrm{C}$ for 7 days. Incidence of infection was determined to be $100 \%$ for a sample of 20 stolons plated onto the modified agar medium. Infected stolons were subsequently used as naturally infected inoculum for soil fumigation experiments in the field.

Crowns. In May 2009, 50 crowns sampled from wilted strawberry plants ('Tamar') in a fruiting crop in the Sharon area of Israel that exhibited approximately $50 \%$ crown rot were plated on the modified agar medium for $M$. phaseolina to determine incidence (\%) of infection. M. phaseolina was recovered from all sampled crowns. Crowns from diseased plants were stored at $4^{\circ} \mathrm{C}$ for 7 days and served as naturally infected inoculum for soil fumigation experiments in the field.

Survival of M. phaseolina in soil under laboratory and greenhouse conditions. A sandy, nonfumigated soil (91\% sand, $9 \%$ clay, $\mathrm{pH} 7.2$, field moisture capacity of $21 \%$ ) used in survival experiments in this study originated from strawberry fields in the Sharon area. Sclerotia of isolate M1 (experiment 1) and M2 (experiment 2) were incorporated into the soil at a concentration of 14,300 and $16,000 \mathrm{sclerotia} / \mathrm{g}$ of soil for the two survival experiments, respectively. The soils were filtered through a 2-mm sieve before inoculation and adjusted to field capacity ( $22 \%$ moisture content). Samples of each of the filtered soils were placed in 500-ml pots (250 $\mathrm{g} / \mathrm{pot}$ ) and kept moist by watering once a week with $100 \mathrm{ml}$ of tap water. The pots were incubated at three different temperatures: 25 and $35^{\circ} \mathrm{C}$ and under greenhouse conditions where soil temperatures ranged from 18 to $32^{\circ} \mathrm{C}$ to mimic conditions in commercial greenhouses. In both experiments, three replicate pots were used for each treatment, and 5-g soil samples were collected from each pot every 2 to 10 weeks over 42 and 63 weeks for experiments 1 and 2, respectively. Serial dilutions of each soil sample were prepared in sterile distilled water (10- to 100-fold dilutions), and a $0.2-\mathrm{ml}$ aliquot of each dilution was spread onto each of five replicate plates of the $M$. phaseolina agar medium for each soil sample-treatment-sampling date to determine number of $M$. phaseolina $\mathrm{CFU}$ per gram soil. The plates were incubated at $25^{\circ} \mathrm{C}$ for 5 days in a completely randomized design. Survival over time was calculated as a percentage of the original inoculum at time 0 (day of inoculation of the agar plates). The control treatment consisted of replicate 5-g samples of nonfumigated field soil collected from each of the pots prior to inoculation with $M$. phaseolina. A dilution series of each of the control soil samples was prepared similarly (10- to 100-fold) and plated on the M. phaseolina agar medium.

Inoculation of plants under soil heat and water stress. Plants of 'Tamar' strawberry were received from a certified nursery (Yehuda Romano Nurseries Ltd., Tel Yitzhak, Israel), where they had been produced from nursery runners, and were then potted in soilless coconut and styrofoam (3:1, vol/vol) medium (Shaham Givat Ada, Givat Ada, Israel) (0.75 liter/pot). The coconut/styrofoam medium is used by most commercial nurseries in Israel. Each plant was inoculated by watering each pot with $50 \mathrm{ml}$ of sterile water containing $10^{5}$ sclerotia/ml of each of isolate M1 and M3 of $M$. phaseolina. Inoculum was prepared by adding dried sclerotia to the water to achieve the final concentrations. The experiment was laid out in a two-way factorial design with plants incubated at two soil temperatures $\left(25\right.$ and $\left.30^{\circ} \mathrm{C}\right)$ under 12-h day and 12-h night conditions, with two water stress treatments (plants irrigated with water at $200 \mathrm{ml} /$ pot every 4 or 10 days, with the latter mimicking water stress conditions because plants displayed symptoms of wilting at each watering). Each treatment combination was replicated five times, with five pots/replication/treatment. The experiment was set up in a randomized complete block design. Noninoculated plants exposed to each of the four treatment combinations served as the control treatments. Percent plant mortality was recorded $7,10,14$, $17,18,21,24,35,40,42,49,56,60$, and 84 days after inoculation. The experiment was conducted twice, once for each isolate of $M$. phaseolina. The interaction of temperature and water stress on 
plant mortality was assessed using a factorial analysis of variance (ANOVA) for a randomized complete block design.

Inoculation of strawberry plants with different sources of inoculum of M. phaseolina. An experiment was set up in a two-way factorial design to evaluate the effect of different sources of inoculum of M. phaseolina on infection of 'Tamar' strawberry plants. Isolates of $M$. phaseolina from seven plant hosts were evaluated at each of two soil temperatures $\left(25\right.$ and $\left.30^{\circ} \mathrm{C}\right)$. The hosts of origin included spikenard (Aralia sp.), pincushion protea (Leucospermum sp.), protea (Leucadendron sp.), muskmelon (Cucumis melo), watermelon (Citrullus lanatus), almond (Amygdalus communis), and strawberry (isolate M1 and M9 in experiments 1 and 2, respectively). Each strain was inoculated at a concentration between $1 \times$ $10^{4}$ and $2 \times 10^{4}$ sclerotia/ml and the inoculated plants were incubated at 25 or $30^{\circ} \mathrm{C}$, as described above. For each isolate, 10 plants (replicates) were subjected to each of the soil temperature treatments $\left(25\right.$ and $\left.30^{\circ} \mathrm{C}\right)$ and 10 plants were used for each of the noninoculated control treatments (maintained at each of 25 and $30^{\circ} \mathrm{C}$ ). Plants were arranged in a completely randomized design. The experiment was repeated. Percent plant mortality was recorded every 7 days over 105 days following inoculation. Data were analyzed using a two-way ANOVA.

Control of $M$. phaseolina by soil fumigation under field conditions. Three experiments were conducted during establishment of a strawberry crop in September 2006 in the Rehovot area of Israel, and in September 2008 and 2009 in the Sharon area, to assess management of different types of inocula of M. phaseolina. The experiments consisted of the following soil-fumigation treatments: methyl bromide (Bromine Compounds Ltd., Be'erSheva, Israel) applied at $500 \mathrm{~kg} / \mathrm{ha}$, metam sodium (Edochem Super; Taminco N.V., Tokyo) applied at 44 and 73 liters/ha, 60.8\% 1,3dichloropropene $+33.3 \%$ chloropicrin (TeloDrip; Dow AgroSciences LLC., Indianapolis, IN) applied at $500 \mathrm{~kg} / \mathrm{ha}, 100 \%$ chloropicrin (Tripicrin; TriCal Inc., Hollister, CA) applied at 200 and $400 \mathrm{~kg} / \mathrm{ha}$, and a nonfumigated control treatment. In 2006, the methyl bromide treatment, metam sodium at 44 liters/ha, and Telodrip (combination of 3-dichloropropene and chlropicrin) treatments were evaluated; in 2008, the methyl bromide, metam sodium (at both 44 and 73 liters/ha), Telodrip, and chloropicrin (at both 200 and $400 \mathrm{~kg} / \mathrm{ha}$ ) treatments were evaluated; and, in 2009, methyl bromide, metam sodium (at 44 and 73 liters/ha), and chloropicrin (at 200 and $400 \mathrm{~kg} / \mathrm{ha}$ ) treatments were evaluated. Fumigants were each administered via drip irrigation through two plastic pipes (16 $\mathrm{mm}$ in diameter) per plot placed on the soil surface. Fumigation was conducted under impermeable polyethylene plastic sheets (40 $\mu \mathrm{m}$ thick; A. A. Politiv Ltd., Kibbutz Einat, Israel) spread on the surface of the plots, including the nontreated control plots, to avoid confounding the limited amount of soil solarization caused by the plastic with the effects of the fumigation treatments. Each plot was 10 by $1 \mathrm{~m}$, with four replicate plots/treatment arranged in a completely randomized design.

The different inoculum types of M. phaseolina (sclerotia versus infected strawberry crowns or stolons) were buried in nylon mesh bags in the soil (91\% sand, $9 \%$ clay, pH 7.2; field capacity $21 \%$ ) in each plot prior to applying fumigation treatments. In the first two experiments, each bag contained $100 \mathrm{~g}$ of moist field soil collected from the experiment site plus 10 segments of infected stolons (each $2 \mathrm{~cm}$ in length), or $10 \mathrm{~g}$ of soil containing sclerotia produced in the laboratory (at 520 and 469 sclerotia/g of soil in experiments 1 and 2 , respectively). In experiment 3,10 segments of naturally infected strawberry crowns (each approximately $1 \mathrm{~cm}$ in diameter) were used instead of infected stolons. The bags were buried 10 or $30 \mathrm{~cm}$ deep in a completely randomized design in each of four replicate plots.

Buried bags were retrieved from both fumigated plots and nonfumigated control plots 7 days after applying the fumigation treatments. Subsequently, the stolons and crowns were washed under running tap water; surface sterilized for $10 \mathrm{~s}$ in $70 \%$ ethanol, then for $3.5 \mathrm{~min}$ in $3 \%$ sodium hypochlorite; and plated on the $M$. phaseolina-modified agar medium. Percent survival of each of the types of inoculum was determined by calculating the mean number of infected stolons or crowns that yielded M. phaseolina growth on the modified agar medium compared with inoculum maintained in the laboratory at $25^{\circ} \mathrm{C}$ (control treatment which was sampled prior to setting up the field experiment and again when inoculum was removed from field plots at the termination of each experiment). Control inoculum maintained at $25^{\circ} \mathrm{C}$ in the laboratory included five replications of 10 samples of stolons, crowns, and sclerotia. From each nylon bag containing sclerotia-infested soil, 5-g samples of soil were used to prepare serial dilutions in sterile distilled water (10- to 100-fold dilutions), and an aliquot of each replicate dilution per sample per treatment was plated onto the $M$. phaseolina-modified agar medium to determine numbers of CFU per gram of soil. Mean sclerotium survival (numbers of viable sclerotia per gram of soil) was calculated for each replication of each treatment as CFU per gram of soil and compared with mean incidence (\%) of infected stolons and crowns that generated viable cultures of M. phaseolina.

Statistical analyses. For the plant mortality experiments, the area under the mortality progress curve (AUMPC) was calculated on the basis of plant mortality assessments over the duration of each experiment; the period used for calculating AUMPC values extended from planting to the last mortality assessment. Because the duration varied among experiments, the relative (R) AUMPC was calculated by dividing the AUMPC values by the duration of the experiment and expressed as a percentage. Data from the replicated plots were analyzed with two-way ANOVAs for the main effects of soil temperature and soil moisture stress, or soil temperature and host of origin of the M. phaseolina isolates. When the $F$ statistic of an ANOVA was significant at $P \leq 0.05$, the least significant difference was calculated according to Tukey's honestly
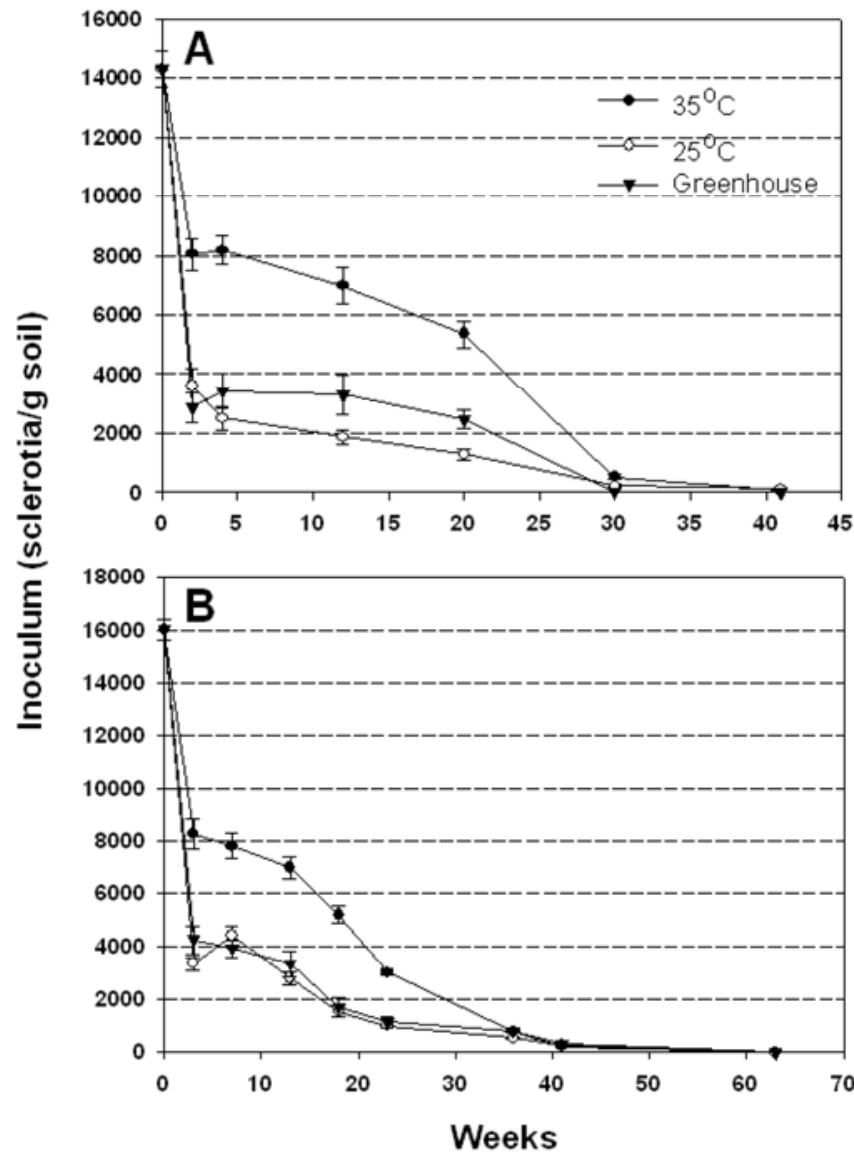

Fig. 1. Survival of Macrophomina phaseolina sclerotia/g soil under different soil temperatures (constant $25^{\circ} \mathrm{C}$, constant $35^{\circ} \mathrm{C}$, or greenhouse conditions fluctuating from 18 to $32^{\circ} \mathrm{C}$ ), expressed as CFU/gram of soil over time in each of two experiments (A and $\mathbf{B})$. Each data point represents the mean and standard error of three replicate plots, each containing five samples. 
significant difference test. Statistical analyses for the type of inoculum experiments were conducted using Tukey's multiple comparison test at a significance level of $P<0.05$. Statistical analyses for all data were performed using JMP (version 5; SAS Institute Inc., Cary, NC).

\section{Results}

Survival of M. phaseolina in soil. In each repeat of this experiment, $M$. phaseolina was not detected in nonfumigated, noninoculated control soils sampled prior to inoculation of soils for evaluation of survival of the pathogen at different soil temperatures (data not shown). In inoculated soils, sclerotia viability declined over time from a mean of $>14,000$ and approximately 16,000 sclerotia/g of soil at the time of inoculation in experiments 1 and 2, respectively, to nondetectable levels after approximately 30 to 40 weeks (Fig. 1). Sclerotia viability declined significantly more rapidly in soils held at $25^{\circ} \mathrm{C}$ and at fluctuating soil temperatures of 18 to $32^{\circ} \mathrm{C}$ than in soils maintained at $35^{\circ} \mathrm{C}$ (Fig. 1) for up to 20 weeks (experiment 1) or 23 weeks (experiment 2), as determined by plating soil onto the modified agar medium for isolation of $M$. phaseolina (Fig. 2). In experiment 1 , the differences in results between $25^{\circ} \mathrm{C}$ and the fluctuating soil temperature regime were insignificant $(P=0.05)$ from 3 to 30 weeks compared with significant differences for these treatments throughout the same period in experiment 2 (Fig. 1). Colonies of M. phaseolina recovered from soil were identified and differentiated from colonies of other fungi based on fan-like, restricted mycelial growth on the modified agar medium, which enabled accurate enumeration of viable propagules of the pathogen (Fig. 2).

Plant mortality under soil heat and water stress. Dead strawberry plants were not observed in noninoculated control soil kept at 25 or $30^{\circ} \mathrm{C}$ with or without water stress (data not shown). A significantly greater incidence (\%) of plant mortality was caused by $M$. phaseolina in soil held at 30 compared with $25^{\circ} \mathrm{C}$ in both experiments, and water stress did not have a significant effect on plant survival at each of these temperatures. Mortality of plants grown in soil at $30^{\circ} \mathrm{C}$ reached $100 \%$ after 14 days, regardless of the presence or absence of water stress in either repeat of the experiment (Fig. 3A and B). For plants grown at $25^{\circ} \mathrm{C}$, a low incidence of plant mortality was first observed in infested soil 14 to 24 days after inoculation, and reached 80 to $90 \%$ mortality after 80 days in the two repeats of this experiment (Fig. 3A and B). The interaction between the two main factors (temperature and moisture stress) was insignificant for the final incidence of plant mortality for both experiments $(P=0.25$ and $P=0.21$ for experiments 1 and 2 , respectively) (Table 1). For relative AUMPC (RAUMPC) values, the interaction between the two main factors was significant in each experiment $(P=0.003$ and $P=0.002$ for experiments 1 and 2 , respectively). For plants grown at $25^{\circ} \mathrm{C}$, water stress reduced the RAUMPC values significantly in experiment 2 only but the difference in mean RAUMPC values for water-stressed plants versus nonstressed plants was only $6 \%$ compared with $46 \%$ mortality for plants maintained at 30 versus $25^{\circ} \mathrm{C}$ (Table 1).

Effect of $M$. phaseolina isolates from various hosts on strawberry plant mortality. The interaction of soil temperature-host plant from which the isolates of M. phaseolina were obtained was insignificant in the ANOVA $(P=0.678)$. The main effect of temperature was significant $(P=0.008)$, whereas the main effect of host of origin of the isolates was insignificant $(P=0.85)$. Strawberry plant mortality declined more rapidly for plants grown at 30 versus $25^{\circ} \mathrm{C}$ for all isolates of $M$. phaseolina tested, regardless of the host of origin (data not shown). At $30^{\circ} \mathrm{C}$, mortality of strawberry plants reached $100 \%$ after 10 days, whereas incidences of 80 to $100 \%$ mortality were only recorded 15 weeks after inoculation for plants grown at $25^{\circ} \mathrm{C}$. Noninoculated control plants remained healthy. No significant differences were observed in incidence of mortality of strawberry plants grown in inoculated potting medium infested with isolates of $M$. phaseolina from various hosts, regardless of soil temperature (Table 2).

Survival of $M$. phaseolina in field soil with different fumigation treatments. Average soil temperatures recorded in the field at depths of 10 and $30 \mathrm{~cm}$ under the polyethylene mulch from July to

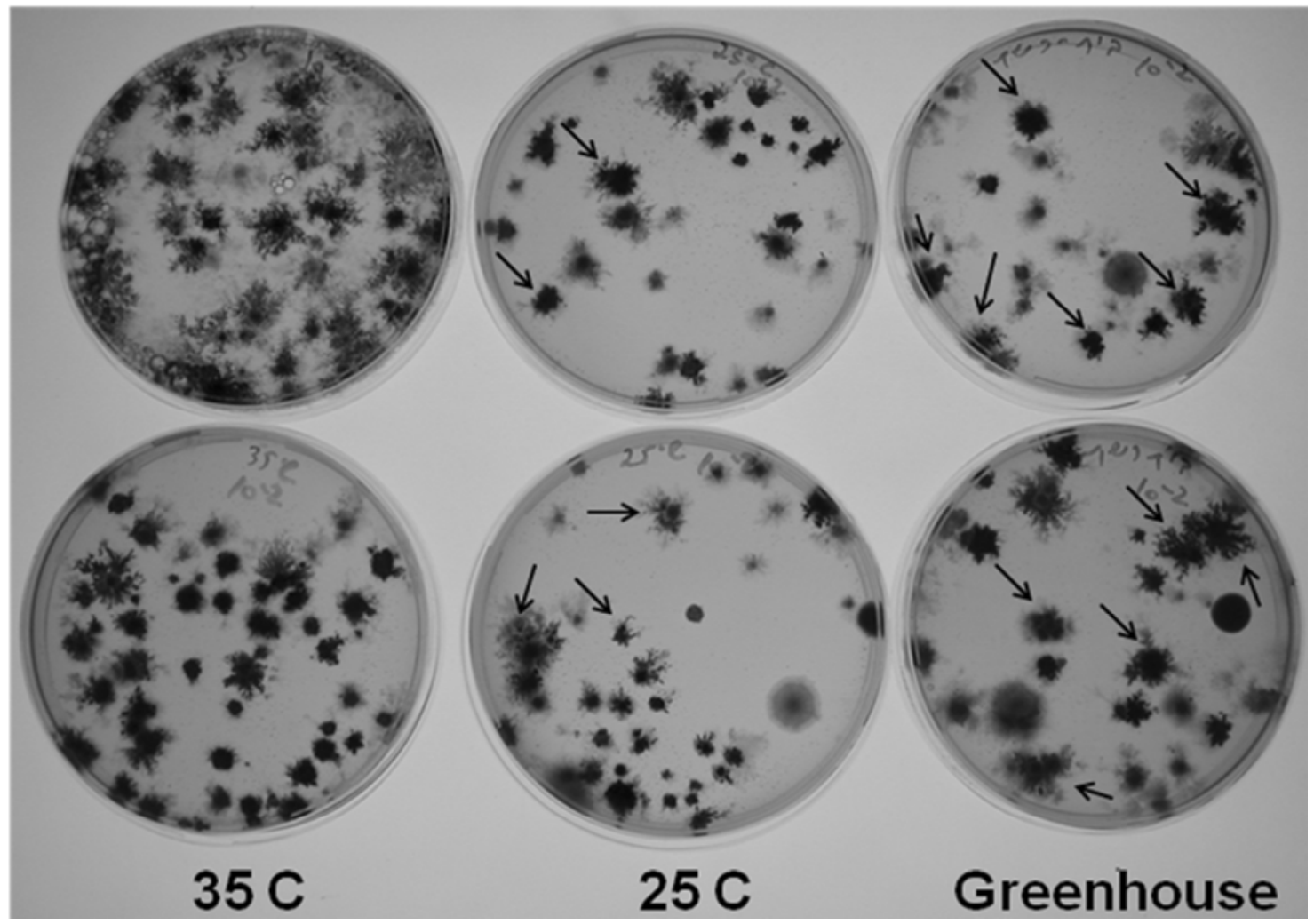

Fig. 2. Isolation of sclerotia of Macrophomina phaseolina from soil exposed to different soil temperatures (constant $25^{\circ} \mathrm{C}$, constant $35^{\circ} \mathrm{C}$, and greenhouse conditions fluctuating from 18 to $32^{\circ} \mathrm{C}$ ), plated on a modified agar medium for detection of the pathogen. Recovered colonies of $M$. phaseolina from soil were identified based on fanlike, restricted growth on the medium, which differentiated this fungus from colonies of other fungi. Arrows point to some of the colonies with typical growth of $M$. phaseolina. 
September during the years that the three experiments were carried out were $37 \pm 2$ to $40 \pm 2{ }^{\circ} \mathrm{C}$. Prior to burial in soil, M. phaseolina was recovered from $100 \%$ of the crowns and stolons used as inoculum after surface-sterilization and plating of the inocula on the modified agar medium. Methyl bromide and metam sodium were the most effective of the soil-fumigation treatments evaluated for eradication of different types of inoculum of the pathogen in all three field experiments. Application of TeloDrip was as effective statistically as the former two fumigation treatments in experiment 1 but not in experiment 2 (and was not evaluated in experiment 3 ) (Table 3).

In experiment 1 , viability of $M$. phaseolina sclerotia declined in control plots by approximately 55 and $67 \%$ at $10-$ and $30-\mathrm{cm}$ depths, respectively, relative to survival of sclerotia maintained in the laboratory at $25^{\circ} \mathrm{C}$ (data not shown). Similarly, viability of inocula in stolons declined in control plots by 71 and $75 \%$ at 10 and 30-cm depths, respectively, compared with stolons stored in soil in the laboratory (data not shown). Fumigation with metam sodium and methyl bromide caused $100 \%$ mortality of sclerotia and stolon inoculum at both 10- and 30-cm soil depths, except for inoculum in infected stolons buried $30 \mathrm{~cm}$ deep, where $5 \%$ of the stolons still had viable inoculum of $M$. phaseolina after fumigation with metam sodium at 44 liter/ha. In experiment 1, the TeloDrip fumigation treatment was as effective statistically as methyl bromide and metam sodium fumigation treatments for reducing survival of $M$. phaseolina sclerotia at both depths in experiment 1 , although this treatment did not completely kill all of the viable

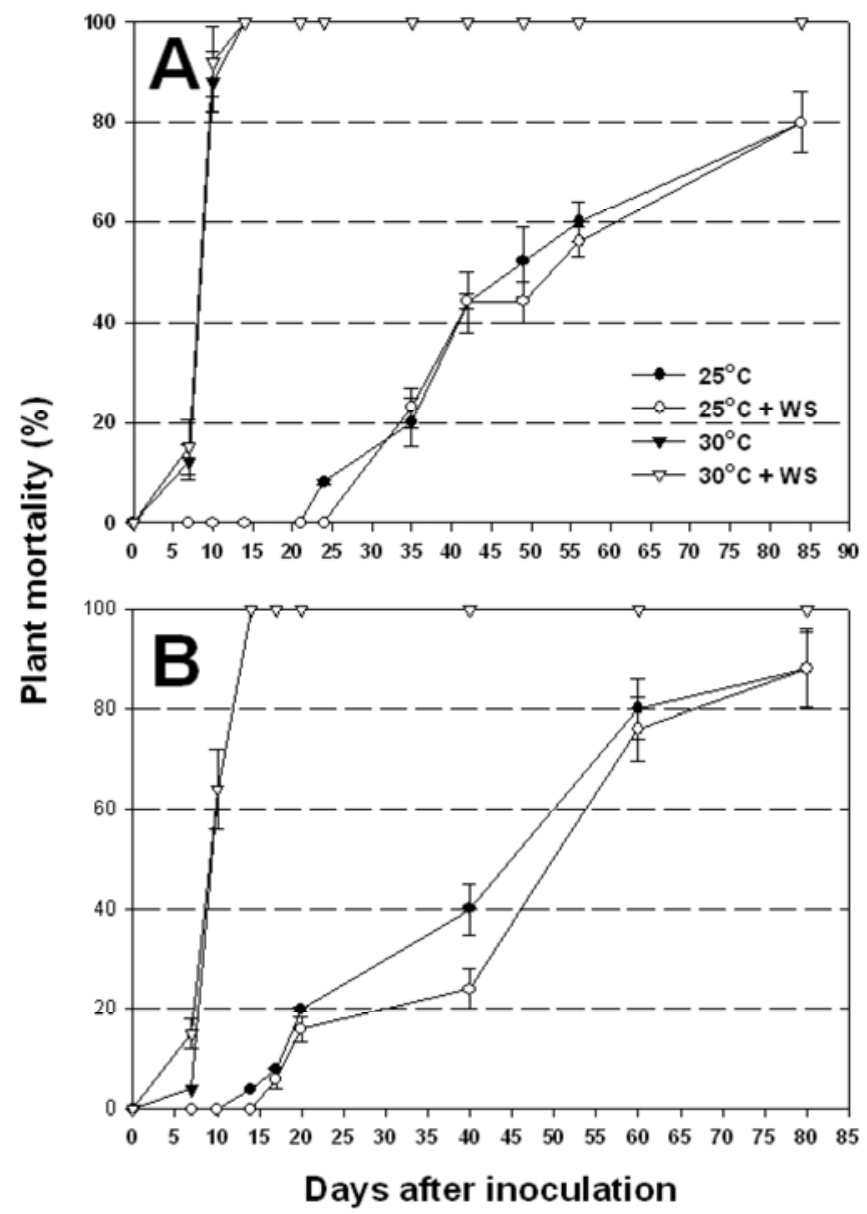

Fig. 3. Strawberry plant mortality (percent plants dead) over time (days after inoculation) in soil inoculated with Macrophomina phaseolina and maintained at soil temperatures of 25 or $35^{\circ} \mathrm{C}$, with or without soil moisture stress (water stress $=$ WS), in two experiments (A and B). Plants were irrigated with $200 \mathrm{ml}$ water every 4 or 10 days (the latter to mimic water stress because plants were displaying symptoms of wilting at each watering). Each data point represents the mean and standard error of 25 replicate plants. sclerotia at either depth (viability of sclerotia at 10 - and $30-\mathrm{cm}$ depths was reduced by 99.9 and $96.0 \%$, respectively; Table 3). TeloDrip killed all inoculum from infected stolons buried $10 \mathrm{~cm}$ deep in experiment 1 but was significantly less effective than methyl bromide at reducing survival of inoculum in infected stolons buried $30 \mathrm{~cm}$ deep in that experiment (Table 3).

In experiment 2 , viability of M. phaseolina sclerotia buried 30 $\mathrm{cm}$ deep declined by approximately $45 \%$ compared with sclerotia maintained in the laboratory at $25^{\circ} \mathrm{C}$ (data not shown). Similar to experiment $1,100 \%$ mortality of sclerotia was recorded for the metam sodium and methyl bromide treatments (Table 3). However, in contrast to results for TeloDrip fumigation in experiment 1, viability of sclerotia buried $30 \mathrm{~cm}$ deep was not affected significantly by TeloDrip fumigation in experiment 2 (Table 3). Fumigation with chloropicrin applied at 200 or $400 \mathrm{~kg} / \mathrm{ha}$ was as effective as methyl bromide or metam sodium, resulting in $100 \%$ sclerotia mortality (Table 3).

In experiment 3 , viability of $M$. phaseolina inoculum in crowns placed $30 \mathrm{~cm}$ deep in the control plots declined by approximately $40 \%$ compared with inoculum in infected crown tissue maintained in the laboratory at $25^{\circ} \mathrm{C}$ (data not shown). Methyl bromide reduced inoculum viability by $90 \%$, and both rates of metam sodium application reduced inoculum viability by $95 \%$, whereas chloropicrin applied at 200 and $400 \mathrm{~kg} / \mathrm{ha}$ reduced inoculum viability by 55 and $70 \%$, respectively (Table 3 ).

\section{Discussion}

In Israel, strawberry is cultivated primarily during the winter for fresh-fruit markets and is important economically for local consumption as well as winter exports to European markets (8). However, the warm climate of the region is ideal for development of a number of soilborne fungal pathogens of strawberry. The major fungal pathogens affecting strawberry in Israel include Phytophthora cactorum, Rhizoctonia spp., Colletotrichum spp., and, most recently, $M$. phaseolina $(8,11,32,39,40)$. These pathogens cause similar symptoms of wilting and, therefore, it is important to be able to distinguish between the different causal agents to help achieve effective disease control. In recent years, crown and root rot caused by $M$. phaseolina have appeared in many strawberry cultivation areas worldwide $(1-3,14,21)$, indicating the potential for long-term establishment of the pathogen in soils, especially where methyl bromide has been phased out of use. Sclerotia of $M$. phaseolina serve as the primary survival and infection propagules of this pathogen $(20,29)$. Numerous selective media have been used for isolation of $M$. phaseolina from soil and plant tissue $(22,24)$. In this study, a modified agar medium was developed for $M$. phaseolina colony recovery from soil that included the fungi-

Table 1. Effects of soil temperature and water stress on strawberry plant mortality caused by Macrophomina phaseolina ${ }^{\mathrm{w}}$

\begin{tabular}{lccc}
\hline Temperature $\left({ }^{\circ} \mathbf{C}\right)$ & Water stress $^{\mathbf{x}}$ & $\begin{array}{c}\text { Plant mortality } \\
(\boldsymbol{\%})^{\mathbf{y}}\end{array}$ & $\begin{array}{c}\text { RAUMPC } \\
(\boldsymbol{\%})^{\mathbf{z}}\end{array}$ \\
\hline Experiment 1 & & & \\
25 & - & $80.0 \mathrm{~b}$ & $33.9 \mathrm{~b}$ \\
25 & + & $80.0 \mathrm{~b}$ & $33.3 \mathrm{~b}$ \\
30 & - & $100.0 \mathrm{a}$ & $81.3 \mathrm{a}$ \\
30 & + & $100.0 \mathrm{a}$ & $81.5 \mathrm{a}$ \\
Experiment 2 & - & $90.0 \mathrm{~b}$ & $38.1 \mathrm{~b}$ \\
25 & + & $89.0 \mathrm{~b}$ & $32.8 \mathrm{c}$ \\
25 & - & $100.0 \mathrm{a}$ & $82.5 \mathrm{a}$ \\
30 & + & $100.0 \mathrm{a}$ & $81.6 \mathrm{a}$ \\
30 & &
\end{tabular}

${ }^{w}$ Details of the disease progress curves are described in the text. For each experiment, means within a common followed by the same letter do not differ significantly $(P=0.01)$ as determined by Tukey's honestly significant difference test.

${ }^{x}$ Without (-) or with (+) soil water stress, as described in the main text.

${ }^{\mathrm{y}}$ Measured 84 days post inoculation of the soil with sclerotia of $M$. phaseolina.

${ }^{\mathrm{z}}$ RAUMPC $=$ relative area under mortality progress curve. 
cide iprodione to eliminate numerous other pathogenic and saprophytic fungi, and acidification of the medium with lactic acid to reduce bacterial contaminants (9). This medium was used effectively in this study for enumeration of the viability of CFU of $M$. phaseolina from soil in various experiments, including fumigation field trials.

Using this modified, semiselective agar medium, a rapid decline in viability of sclerotia of $M$. phaseolina was observed in moist soil at different temperatures, similar to that reported by Papavisas (27). Likewise, Dhingra and Sinclair (4) reported a 96 to $99 \%$ reduction in sclerotia populations of this pathogen in moist soil over a 2- to 3-week period compared with survival of sclerotia in dry soil. Soil moisture may directly affect sclerotia germination, rendering the propagules more sensitive to antagonistic microflora than sclerotia in dry soils $(4,7)$, particularly because $M$. phaseolina is a poor competitive saprophyte (23). In this study, a soil temperature of $35^{\circ} \mathrm{C}$ may have dried the soil more rapidly than soil maintained at $25^{\circ} \mathrm{C}$, subjecting the sclerotia to less microbial competition or degradation at the higher temperature and, hence, greater plant mortality from soil inoculum at the higher soil temperature.

Soil moisture stress as well as heat stress can predispose crops to M. phaseolina infection, because this fungus is considered thermophilic (23). In this study, water stress generally did not significantly affect strawberry plant mortality caused by this pathogen at 25 or $30^{\circ} \mathrm{C}$, because no difference was observed in plant mortality in water-stressed versus non-water-stressed plants maintained at $30^{\circ} \mathrm{C}$ in either repeat of the experiment; although, for plants grown at $25^{\circ} \mathrm{C}$, mortality was significantly lower in water-stressed versus non-water-stressed plants in one of the two repeats of this experi- ment. At a soil temperature of $30^{\circ} \mathrm{C}$, the incidence of strawberry mortality caused by $M$. phaseolina was significantly greater than mortality of plants grown at $25^{\circ} \mathrm{C}$. Similar results were reported by Edmunds (6), who showed that mortality of inoculated sorghum plants was significantly greater at 40 than $35^{\circ} \mathrm{C}$. In contrast, water stress increased severity of charcoal rot in common bean (19) and of Macrophomina wilt in sorghum (5). Bare-rooted strawberry transplants transferred from field nurseries to production fields can be exposed to extremely stressful conditions, especially water and heat stress. Therefore, infected plants from nurseries can be vulnerable to infection by $M$. phaseolina under elevated soil temperatures. No mortality was observed for strawberry plants grown in noninoculated soil at $35^{\circ} \mathrm{C}$, with or without water stress, indicating that strawberry plants can tolerate heat and soil moisture stress. However, heat stress is detrimental to strawberry plants in the presence of M. phaseolina.

$M$. phaseolina affects a wide plant host range and appears in many geographic locations (23). In some crops, no specialization of isolates of the pathogen toward specific hosts has been observed (e.g., soybean, sorghum, or cotton; 34), whereas isolates of $M$. phaseolina from other hosts (e.g., bean) appear to be host-specific (19). In Israel, M. phaseolina has been detected in various crops that are grown in close proximity, such as strawberry, melon, corn, and bean $(7,30,39)$. In this study, no significant host specialization was observed among isolates of $M$. phaseolina obtained from infected almond, aralia, protea, melon, watermelon, or strawberry when inoculated onto strawberry plants at concentrations of $1 \times$ $10^{4}$ to $2 \times 10^{4}$ sclerotia/ml (39). Nonspecificity highlights the importance of avoiding rotation of strawberry crops with these crops in Israel.

Table 2. Effect of soil temperature on mortality of strawberry plants inoculated with isolates of Macrophomina phaseolina obtained from different plant species $^{\mathrm{z}}$

\begin{tabular}{lccc}
\hline & \multicolumn{2}{c}{ Temperature $\left({ }^{\circ} \mathbf{C}\right)$} & \\
\cline { 2 - 3 } Isolate source & $\mathbf{2 5}$ & $\mathbf{3 0}$ & Main effect of isolate source \\
\hline Spikenard (Aralia sp.) & 31.1 & 71.6 & $51.4 \mathrm{a}$ \\
Muskmelon (Cucumis melo) & 16.5 & 50.9 & $33.7 \mathrm{a}$ \\
Watermelon (Citrullus lanatus) & 38.8 & 37.4 & $47.6 \mathrm{a}$ \\
Protea (Leucospermum sp.) & 31.8 & 43.0 & $37.7 \mathrm{a}$ \\
Protea (Leucadendron sp.) & 30.3 & 54.4 & $37.4 \mathrm{a}$ \\
Almond (Amygdalus cummunis) & 23.0 & 76.7 & $42.3 \mathrm{a}$ \\
Strawberry (Fragariae ananassa) & $29.9 \mathrm{~b}$ & $55.8 \mathrm{a}$ & $49.8 \mathrm{a}$ \\
Main effect of temperature & $\ldots$ & $\ldots$ \\
\hline
\end{tabular}

${ }_{\mathrm{z}}$ Each mean represents the percent relative area under mortality progress curve (RAUMPC) calculated for 10 replicate plants. Refer to the main text for details on calculation of RAUMPC values. Based on the main effects of temperature (last row in the table) and source of isolate of M. phaseolina (last column) from the analyses of variance, means with the same letter do not differ significantly $(P=0.01)$ based on Tukey's honestly significant difference test. For each soil temperature evaluated, there were no significant differences in mean RAUMPC values among isolates from each of the seven host species.

Table 3. Survival of inocula of Macrophomina phaseolina buried 10 or $30 \mathrm{~cm}$ deep in soil and then exposed to fumigants in three field experiments in Israel ${ }^{\mathrm{y}}$

\begin{tabular}{|c|c|c|c|c|c|c|}
\hline \multirow[b]{3}{*}{ Treatments $^{\mathrm{z}}$} & \multicolumn{4}{|c|}{ Experiment 1 (2006) } & \multirow{3}{*}{$\begin{array}{c}\text { Experiment } 2 \text { (2008) } \\
\text { Sclerotia/g soil } \\
30 \mathrm{~cm}\end{array}$} & \multirow{3}{*}{$\begin{array}{c}\text { Experiment } 3(2009) \\
\text { Crowns }(\%) \\
30 \mathrm{~cm}\end{array}$} \\
\hline & \multicolumn{2}{|c|}{ Sclerotia/g soil } & \multicolumn{2}{|c|}{ Stolons (\%) } & & \\
\hline & $10 \mathrm{~cm}$ & $30 \mathrm{~cm}$ & $10 \mathrm{~cm}$ & $30 \mathrm{~cm}$ & & \\
\hline Control & $235 \mathrm{a}$ & $170 \mathrm{a}$ & $29 \mathrm{a}$ & $25 \mathrm{a}$ & $257 \mathrm{a}$ & $60 \mathrm{a}$ \\
\hline Methyl bromide & $0 \mathrm{~b}$ & $0 \mathrm{~b}$ & $0 \mathrm{~b}$ & $0 \mathrm{c}$ & $0 \mathrm{~b}$ & $10 \mathrm{~b}$ \\
\hline Metam sodium 44 & $0 \mathrm{~b}$ & $0 \mathrm{~b}$ & $0 \mathrm{~b}$ & $5 \mathrm{bc}$ & $0 \mathrm{~b}$ & $5 \mathrm{~b}$ \\
\hline Metam sodium 73 & - & - & - & - & $0 \mathrm{~b}$ & $5 \mathrm{~b}$ \\
\hline TeloDrip & $3 \mathrm{~b}$ & $30 \mathrm{~b}$ & $0 \mathrm{~b}$ & $10 \mathrm{~b}$ & $273 \mathrm{a}$ & - \\
\hline Chloropicrin 200 & - & - & - & - & $0 \mathrm{~b}$ & $45 \mathrm{ab}$ \\
\hline Chloropicrin 400 & - & - & - & - & $0 \mathrm{~b}$ & $30 \mathrm{ab}$ \\
\hline
\end{tabular}

${ }^{y}$ Means in each column (number of viable sclerotia/gram of soil or percent stolons and crowns with viable inoculum of M. phaseolina compared with survival in soil maintained at $25^{\circ} \mathrm{C}$ in a laboratory) followed by the same letter are not significantly different $(P<0.05)$ according to Tukey's honestly significant different test; $-=$ not determined. Each data point is the mean of four replicate plots. Refer to the main text for details of how inoculum was produced and how viability of the pathogen was measured on a semiselective agar medium at intervals over the duration of each experiment.

${ }^{z}$ Control plots consisted of each inoculum type buried in nonfumigated field soil for the duration of each experiment. Methyl bromide (Bromine Compounds Ltd., Be'erSheva, Israel) was applied by drip irrigation at $500 \mathrm{~kg} / \mathrm{ha}$. Metam sodium (Edochem Super; Taminco N.V., Tokyo, Japan) was applied by drip irrigation at 44 or 73 liters/ha. TeloDrip (Dow AgroSciences LLC., Indianapolis, IN) $=60.8 \%$ 1,3-dichloropropene $+33.3 \%$ chloropicrin applied by drip irrigation at $500 \mathrm{~kg} / \mathrm{ha}$. Chloropicrin Tripicrin (TriCal Inc., Hollister, CA) was applied by drip irrigation at $200 \mathrm{or} 400 \mathrm{~kg} / \mathrm{ha}$. 
In field trials in this study, methyl bromide and metam sodium consistently provided the most effective eradication of several types of inoculum of $M$. phaseolina (sclerotia and naturally infected crowns and stolons). However, fumigation with chloropicrin or the combination of 3-dichloropropene + chloropicrin (TeloDrip) was not consistently as effective as methyl bromide or metam sodium fumigation at both soil depths evaluated in this study. It has been reported that 1,3-dichloropropene gas distribution decreases with increasing distance from the source of fumigation when applied with either drip irrigation or direct shank injection at depths of 2.5 to $30 \mathrm{~cm}$ (38). Similarly, in this study, the efficacy of control of the pathogen using TeloDrip decreased with increasing depth of inoculum of $M$. phaseolina (i.e., survival of sclerotia and stolons buried $10 \mathrm{~cm}$ deep was significantly less than survival $30 \mathrm{~cm}$ deep). In field experiments 1 and 2, TeloDrip did not affect sclerotia viability at a $30-\mathrm{cm}$ depth. The results suggest that alternative fumigants to methyl bromide for control of fungal pathogens such as $M$. phaseolina may not be adequate to maintain healthy strawberry crops.

All fumigated plots were covered with polyethylene mulch prior to treatment, including nonfumigated control plots. A rapid decline in sclerotia viability was evident in the control plots, which may be attributed to elevated soil temperatures under the polyethylene mulch even though the mulches remained on the soil surface for only 10 days. Extended periods of solarization may be an alternative means of control of $M$. phaseolina in combination with other soil amendments; however, when used alone, solarization probably is not feasible for pathogen eradication based on other studies $(12,16,26)$. Survival may also be affected by inoculum type, because bare sclerotia may be more vulnerable to the fungicidal effects of fumigation and solarization compared with inoculum within infected plant tissues such as strawberry stolons and crowns.

In summary, this study demonstrated that survival of sclerotia of M. phaseolina declined more rapidly in soil at 25 versus $35^{\circ} \mathrm{C}$, with limited effects of soil moisture stress on viability at the soil temperature and moisture conditions evaluated. Mortality of strawberry plants caused by $M$. phaseolina was more significantly affected by soil temperature (higher mortality in warmer soils) than soil water stress (deficit), although only two levels of soil moisture were evaluated in this study. Isolates of $M$. phaseolina from various other host crops grown in Israel affected strawberry plants in a similar manner to isolates from strawberry, demonstrating the potential for other crops grown in rotation with strawberry to contribute inoculum of M. phaseolina. Metam sodium proved to be an effective alternative soil fumigant to methyl bromide for control of this pathogen in field trials in this study, whereas fumigants such as chloropicrin were less effective. Further research is needed to evaluate additional alternatives to methyl bromide for $M$. phaseolina control in infested fields.

\section{Acknowledgments}

This research was supported by grant number 132-1250 from the Vegetable Fruit Board and Chief Scientist of the Israeli Ministry of Agriculture. We thank Prof. D. Shtienberg for advice regarding statistical analyses of the data, and T. Shechner (Rimi Chemicals Co. Ltd.) and Y. Cahlon (Soiltech Ltd.) for field fumigation applications.

\section{Literature Cited}

1. Avilés, M., Castillo, S., Bascon, J., Zea-Bonilla, T., Martín-Sánchez, P. M., and Pérez-Jiménez, R. M. 2008. First report of Macrophomina phaseolina causing crown and root rot of strawberry in Spain. Plant Pathol. 57:382.

2. Baudry, A., and Morzieres, J. P. 1993. First report of charcoal rot of strawberry in France. Acta Hortic. 348:485-488.

3. Benli oğlu, S., Yildiz, A., and Döken, T., 2004. Studies to determine the causal agents of soil-borne fungal diseases of strawberries in Aydin and to control them by soil disinfestation. J. Phytopathol. 152:509-513.

4. Dhingra, O. D., and Sinclair, J. B. 1975. Survival of Macrophomina phaseolina sclerotia in soil: effects of soil moisture, carbon:nitrogen ratios, carbon sources, and nitrogen concentrations. Phytopathology 65:236-240.

5. Diourte, M., Starr, J. L., Jeger, M. J., Stack, J. P., and Rosenow, D. T. 1995. Charcoal rot (Macrophomina phaseolina) resistance and the effects of water stress on disease development in sorghum. Plant Pathol. 44:196-202.
6. Edmunds, L. K. 1964. Combined relation of plant maturity, temperature and soil moisture to charcoal stalk rot development in grain sorghum. Phytopathology 54:514-511.

7. Elad, Y., Zvieli, Y., and Chet, I. 1986. Biological control of Macrophomina phaseolina (Tassi) Goid by Trichoderma harzianum. Crop Prot. 5:288-292.

8. Freeman, S., and Gnayem, N. 2004. Effect of plasticulture on strawberry plant production. Small Fruits Res. 4:21-32.

9. Freeman, S., and Katan, T. 1997. Identification of Colletotrichum species responsible for anthracnose and root necrosis of strawberry in Israel. Phytopathology 87:516-521.

10. Freeman, S., and Nicoli, G. 1999. Implementation of IPM: strawberries. Pages 454-472 in: Integrated Pest and Disease Management in Greenhouse Crops. L. Gullino, J. van Lenteren, and Y. Elad, eds. Kluwer Academic Publishers, Dordrecht, The Netherlands.

11. Freeman, S., Shalev, Z., and Katan, J. 2002. Survival in soil of Colletotrichum acutatum and C. gloeosporioides pathogenic on strawberry. Plant Dis. 86:965-970.

12. Hartz, T. K., Carter, W. W., and Bruton, B. D. 1987. Failure of fumigation and solarization to control Macrophomina phaseolina and subsequent muskmelon vine decline. Crop Prot. 6:261-264.

13. Jana, T. K., Singh, N. K., Koundal, K. R., and Sharma, T. R. 2005. Genetic differentiation of charcoal rot pathogen, Macrophomina phaseolina, into specific groups using URP-PCR. Can. J. Microbiol. 51:159-164.

14. Koike, S. T. 2008. Crown rot of strawberry caused by Macrophomina phaseolina in California. Plant Dis. 92:1253.

15. Lele, V. C., and Phatak, H. C. 1965. Leaf blight and dry stalk rot of strawberry caused by Rhizoctonia bataticola. Indian Phytopathol. 18:38-42.

16. Lodha, S., Sharma, S. K., and Aggarwal, R. K. 1997. Solarization and natural heating of irrigated soil amended with cruciferous residues for improved control of Macrophomina phaseolina. Plant Pathol. 46:186-190.

17. Maas, J. L. 1998. Macrophomina leaf blight and dry crown rot and Macrophomina root rot and charcoal rot. Pages 26 and 59 in: Compendium of Strawberry Diseases, 2nd ed. J. L. Maas, ed. American Phytopathological Society, St. Paul, MN.

18. Madkour, M. A., and Aly, M. H. 1981. Cell wall degrading enzymes produced during pathogenesis of Macrophomina phaseolina on strawberry plants. Phytopathol. Z. 100:36-43.

19. Mayék-Pérez, N., López-Castañeda, C., González-Chavira, M., GarciaEspinosa, R., Acosta-Gallegos, J., Martínez de la Vega, O., and Simpson, J 2001. Variability of Mexican isolates of Macrophomina phaseolina based on pathogenesis and AFLP genotype. Physiol. Mol. Plant Pathol. 59:257264.

20. McCain, A. H, Bega, R. V., and Jenkinson, J. L. 1982. Solar heating fails to control Macrophomina phaseolina. (Abstr.)Phytopathology 72:985.

21. Mertely, J., Seijo, T., and Peres, N. 2005. First report of Macrophomina phaseolina causing a crown rot of strawberry in Florida. Plant Dis. 89:434.

22. Meyer, W. A., Sinclair, J. B., and Khare, M. N. 1973. Biology of Macrophomina phaseoli in soil studied with selective media. Phytopathology 63:613-620.

23. Mihail, J. D. 1992. Macrophomina. Pages 134-136 in: Methods for Research on Soilborne Phytopathogenic Fungi. L. S. Singleton, J. D. Mihail, and C. M. Rush, eds. American Phytopathological Society, St Paul, MN.

24. Mihail, J. D., and Alcorn, S. M. 1982. Quantitative recovery of Macrophomina phaseolina sclerotia from soil. Plant Dis. 66:662-663.

25. Mihail, J. D., and Taylor, S. J. 1995. Interpreting variability among isolates of Macrophomina phaseolina in pathogenicity, pycnidium production, and chlorate utilization. Can. J. Bot. 73:1596-1603.

26. Ndiaye, M., Termorshuizen, A. J., and van Bruggen, A. H. C. 2007. Combined effects of solarization and organic amendment on charcoal rot caused by Macrophomina phaseolina in the Sahel. Phytoparasitica 35:392-400.

27. Papavizas, G. C. 1977. Some factors affecting survival of sclerotia of Macrophomina phaseolina in soil. Soil Biol. Biochem. 9:337-341.

28. Pratt, R. G. 2006. A direct observation technique for evaluating sclerotium germination by Macrophomina phaseolina, and effects of biocontrol materials on survival of sclerotia in soil. Mycopathologia 162:121-131.

29. Reichert, I., and Hellinger, E. 1947. On the occurrence, morphology and parasitism of Sclerotium bataticola. Palest. J. Bot. Res. 6:107-147.

30. Reuveni, R., Krikun, J., Nachmias, A., and Shlevin, E. 1982. The role of Macrophomina phaseolina in a collapse of melon plants in Israel. Phytoparasitica 10:51-56.

31. Reuveni, R., and Madar, Z. 1985. The role of Macrophomina phaseolina in mortality of pine seedlings in forest nurseries. J. Phytopathol. 112:161-164.

32. Sharon, M., Freeman, S., Kuninaga, S., and Sneh, B. 2007. Genetic diversity, anastomosis groups and pathogenicity of Rhizoctonia spp. from strawberry. Eur. J. Plant Pathol. 117:247-265.

33. Smith, R. S., and Krugman, S. L. 1967. Control of the charcoal root disease of white fir by fall fumigation. Plant Dis. Rep. 51:671-674.

34. Strand, L. L. 1994. Integrated Pest Management for Strawberries. University of California Press, Oakland, CA. Publ. No. 3351.

35. Su, G., Suh, S. O., Schneider, R. W., and Russin, J. S. 2001. Host specialization in the charcoal rot fungus, Macrophomina phaseolina. Phytopathology 91:120-126.

36. Tjamos, E. C., Antoniou, P. P., Skourtaniotis, A., Kikrilis, E., and Tjamos, 
S. E. 2006. Impermeable plastics and methyl bromide alternatives in controlling soilborne fungal pathogens of strawberries in Greece. Pages 255-257 in: Proc. 12th Congr. Mediterr. Phytopathol. Union, Rhodes, Greece.

37. Tu, J. C. 1985. An improved Mathur's medium for growth, sporulation and germination of Colletotrichum lindemuthianum. Microbiosis 44:87-93.

38. Wang, D., and Yates, S. R. 1999. Spatial and temporal distributions of 1,3dichloropropene in soil under drip and shank application and implications for pest control efficacy using concentration-time index. Pestic. Sci. 55:154-160.

39. Zveibil, A., and Freeman, S. 2005. First report of crown and root rot in strawberry caused by Macrophomina phaseolina in Israel. Plant Dis. 81:1014.

40. Zveibil, A., Horowits, S., and Freeman, S. 2004. Identification, characterization and survival of Phytophthora cactorum, causal agent of crown and leather rot of strawberry in Israel. Phytoparasitica 32:189. 